\title{
Staining the Ground Section of the Tooth Using an Innovative Plant Stain Found in the Pravara Region, India
}

\author{
Deepak M Vikhe ${ }^{1}$, Sanjay G Thete ${ }^{2}$, Chaitra S Mastud ${ }^{3}$, Tejashree Mantri ${ }^{4}$, Prasad N Mhaske ${ }^{5}$, Santoshkumar P Mastud ${ }^{6}$, \\ Pallavi Madanshetty ${ }^{7}$
}

\begin{abstract}
Aims: To assess the staining efficacy of the innovative "Pravara" stain on ground sections of human teeth under a stereomicroscope. In this study, the ground sections were stained with the innovative stain. The stain is obtained from a leafless tree called Terminalia chebula. Terminalia chebula, commonly known as Harad, is found in South Asia from India. Few species are found in the Pravara region of Maharashtra, India.

Materials and methods: A total of 40 extracted teeth were collected and ground sections of each tooth were prepared. The samples were randomly divided into two groups: group I - control (without stain), group II—study group (the samples in this group were stained with the help of innovative "Pravara" stain). The sections were graded from I to III according to the differentiation and contrast of tissues.

Results: The ground sections in group II stained with Pravara stain demonstrated better contrast for structures within sections under a microscope in comparison with group I (control group).

Conclusion: The study demonstrates the efficacy of a new innovative Pravara stain, which is a simple, economical, quick, and effective staining method for the ground sections of the teeth.

Clinical significance: This innovative Pravara stain is cost-effective, saves time, ecofriendly, and highlights the anatomical structures more effectively and does not fade easily with time.

Keywords: Ground section, Histopathology, Pravara stain.

The Journal of Contemporary Dental Practice (2020): 10.5005/jp-journals-10024-2904
\end{abstract}

\section{INTRODUCTION}

The hard tissue component of the tooth consists of enamel, cementum, and dentin. There are different methods to study and observe the histology of these tissues; one of them is the preparation of ground sections without staining them. This section depends upon the degree of intensity of light passing through the crystal arrangement. ${ }^{1}$ To highlight the boundaries and better identification of components of the tooth, staining of specimens could be done, which will provide a better contrast. ${ }^{1}$ Ground section of the tooth is the gold standard method to study the anatomy of teeth or for any hard tissue findings, but the preparation of the ground section and decalcification is time-consuming and can be cumbersome for an untrained person. According to many researchers to observe or view the different components that constitute the tissue, staining with decalcification of tissues is important. ${ }^{2,3}$

Several factors determine how a thin tooth section is grounded and studied including its shape, thickness, and its use. With the available information, the present study was conducted to stain the ground section of the tooth using an innovative plant stain. The innovative stain is obtained from leafless tree called as Terminalia chebula that belongs to the combretaceae family. Terminalia chebula, commonly known as harad or chebulic myrobalan, is found in South Asia. Few species are found in Pravara region of Maharashtra, India.

\section{Aım}

To assess the effective staining of the innovative "Pravara" stain on the ground section of the tooth under a stereomicroscope.

\footnotetext{
1,7Department of Prosthodontics, Rural Dental College and Hospital, Pravara Institute of Medical Science (DU), Pravara Medical Trust, Loni, Maharashtra, India

${ }^{2}$ Department of Oral Pathology and Microbiology, Rural Dental College, Pravara Institute of Medical Science (DU), Loni, Maharashtra, India

${ }^{3}$ Department of Orthodontics, Dr DY Patil Vidyapeeth, Dr DY Patil Dental College and Hospital, Pimpri, Pune, Maharashtra, India

${ }^{4}$ Department of Oral Medicine and Radiology, MIDSR Dental College, Loni, Maharashtra, India

${ }^{5}$ Department of Prosthodontics, Bharati Vidyapeeth University Dental College, CBD Belapur, Navi Mumbai, Maharashtra, India

${ }^{6}$ Department of Oral Medicine and Radiology, Dr DY Patil Vidyapeeth. Dr DY Patil Dental College and Hospital, Pimpri, Pune, Maharashtra, India

Corresponding Author: Deepak M Vikhe, Department of Prosthodontics, Rural Dental College and Hospital, Pravara Institute of Medical Science (DU), Pravara Medical Trust, Loni, Maharashtra, India, Phone: +91 9822811117, e-mail: drdeepak_mvikhe@yahoo. com

How to cite this article: Vikhe DM, Thete SG, Mastud CS, et al. Staining the Ground Section of the Tooth Using an Innovative Plant Stain Found in the Pravara Region, India. J Contemp Dent Pract 2020;21(10): 1113-1116.

Source of support: Dr K Linge (Family Physician, Pravara Medical Tust)

Conflict of interest: None
}

() The Author(s). 2020 Open Access This article is distributed under the terms of the Creative Commons Attribution 4.0 International License (https://creativecommons. org/licenses/by-nc/4.0/), which permits unrestricted use, distribution, and non-commercial reproduction in any medium, provided you give appropriate credit to the original author(s) and the source, provide a link to the Creative Commons license, and indicate if changes were made. The Creative Commons Public Domain Dedication waiver (http://creativecommons.org/publicdomain/zero/1.0/) applies to the data made available in this article, unless otherwise stated. 


\section{Objective}

To study the hard tissue architecture of the tooth by effective staining of innovative "Pravara" stain on the ground section of the tooth.

\section{Materials and Methods}

A total of 40 teeth that were extracted for orthodontic reasons were selected from the Oral Surgery Department for the study, Rural Dental College, Loni. Institutional ethical clearance was obtained from the ethical committee before the start of the study.

\section{"Pravara" Stain Preparation}

Terminalia chebula was collected from the local market from local farmers in winter season and authenticated with the help of a senior botanist. The seeds of the dried fruits from this tree were crushed with the help of mortar and pestle to obtain a powder. The fine powder obtained from the dried fruits of this tree is commonly called as Harad. ${ }^{4}$ The $0.35 \mathrm{~g}$ powder of T. chebula (Harad) stain was dissolved in $100 \mathrm{~mL}$ autoclaved distilled water and filtered with a filter paper. Then prepared stain was stored in an amber-colored bottle at room temperature.

\section{Preparation of Ground Sections and Staining}

The ground section of each tooth was prepared with proper care using a standard protocol. All the collected teeth were kept in hydrogen peroxide solution for 24 hours followed by a rinse in sterile water. The samples obtained were randomly divided into two groups: group I and group II. Then, with the help of carborundum stone grinding of these teeth was done to obtain thin ground sections.

Grounded sections were cleared in xylene for 1 minute. Then, for 3-4 minutes each sections were hydrated through consecutive gradations of alcohol. ${ }^{2}$ Following this, the slides were kept in distilled water for 2-3 minutes. $^{5}$

Group I (control or unstained sections): on completion of the abovementioned procedure, the slides were cleaned, dried, and mounted on a microscopic slide and viewed.

Group II-study group: the samples in this group were stained with the help of an innovative "Pravara" stain. After following all the routine procedures, finally, sections in group II were stained with the prepared solution of the innovative "Pravara" stain for 10 minutes. Sections were decolorized with $95 \%$ alcohol until the alcohol ran clear (15 seconds). The section was dried and cleared with xylene to mount on the stereomicroscopic slide using DPX and viewed under a microscope for further findings. 5,6

The grading of sections was done from grade I to III according to the differentiation and contrast of tissues by innovative Pravara stain (Table 1). ${ }^{7}$ Two oral pathologists were blinded to the method and were asked to report the slides focused. The stained sections were viewed after 6 months to assess the intensity of the stain.

Table 1: Grading for differentiation and contrast of tissues

\begin{tabular}{ll}
\hline Grade I & Tissues distinguishable with difficulty \\
Grade II & Tissues moderately distinguishable \\
Grade III & Tissues brightly contrasted \\
\hline
\end{tabular}

\section{Results}

In group II, 15 samples of the ground section of teeth were graded III, which showed $75 \%$ of staining, and 5 samples were graded II, which showed $25 \%$ of staining. In group I, 15 samples of ground section of teeth were graded II, which showed $80 \%$ staining, 3 samples were graded $\mathrm{I}$, which showed $10 \%$ of staining, and only 2 samples were graded III, which showed $10 \%$ of staining. The approximate average of the grades was calculated, tissues of sections were best differentiated, and contrast was observed better in group II by innovative Pravara stain (Table 2). Above grading was given by both the oral pathologists, without any variations. All the samples in group II showed positive staining with different degrees of grading, whereas in group I (without staining) they do not show the proper degree of contrast within structures/tissues compared to group II (Table 2). Control group I (without stain) does not show any contrast within tissues (Fig. 1) (ground section of the tooth without staining). Application of staining in group II by innovative "Pravara" stain on the ground section of the tooth showed good results with the highlighted structures as shown in Fig. 2 (ground section of the tooth with staining by innovative "Pravara" stain).

\section{Discussion}

To study the anatomy of the tooth to visualize under a compound microscope has always been an insidious and difficult aspect as the structure of hard and soft tissues is distorted following decalcification and histological processing. ${ }^{1}$ It is also a time-consuming, difficult procedure. ${ }^{8}$ Different studies related to dental caries, cementum

Table 2: Grading for differentiation and contrast of tissues in both groups (approximate average of the grades of the intensity of differentiation and contrast of tissues by two oral pathologists for 20 tooth sections in each group)

\begin{tabular}{lll}
\hline Grade & Group I & Group II \\
\hline 1 & $3(10)$ & 0 \\
2 & $15(80)$ & $5(25)$ \\
3 & $2(10)$ & $15(75)$ \\
\hline
\end{tabular}

Group I = \% nonstained group; Group II = \% stained group

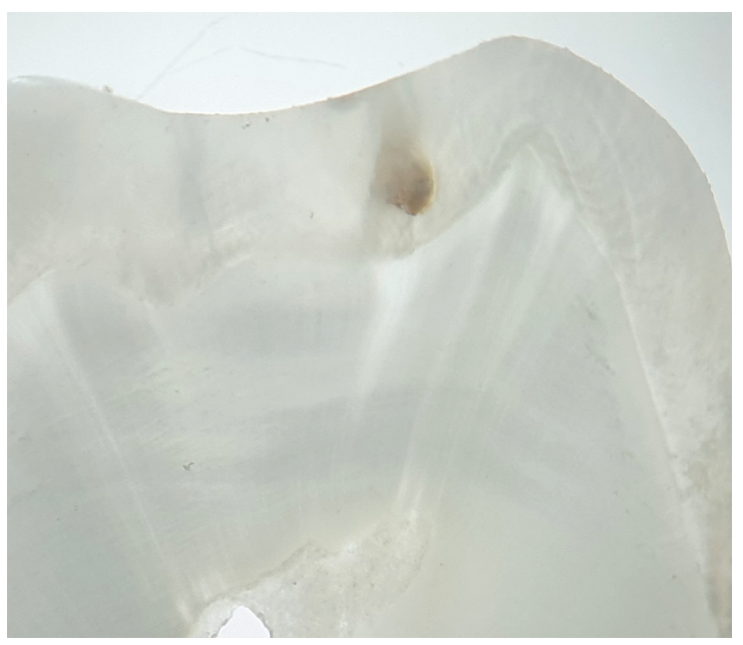

Fig. 1: Ground section of the tooth without staining 


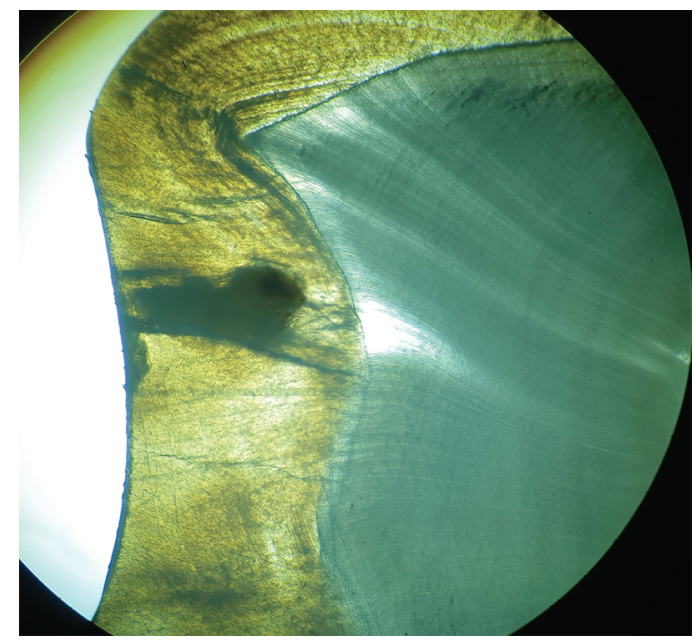

Fig. 2: Ground section of the tooth with staining by innovative "Pravara" stain. Tissues can be appreciated very well

annulation, bone morphologies, age determination, etc., can be done with the help of ground sections. . $^{5-12}$

The techniques used for histological staining had significant changes through years by many ways such as chemical, molecular biology assays, and immunological techniques. Earlier pathologists used the readily available chemicals to prepare stains for microscopic studies. ${ }^{13}$ For a long time, researchers have been searching substitutes for hematoxylin and eosin. Some stains reported by Lillie that were used in the research are Phenocyanin TC, Gallein, Fluorone Black, Alizarin Cyanin BB, and Alizarin Blue S. The authors mentioned Celestin blue $B$ with an iron mordant to be quite successful if prepared. ${ }^{14-17}$ The application of stain Mordant Blue 3 also was reported by Hogg and Simpson ${ }^{18}$ and Llewellyn. ${ }^{19}$ None of the abovementioned stains has gained much popularity. In a study done by Shukla of normal decalcified teeth, cementum and its lesions were better observed when it was stained using cresyl violet stain. ${ }^{7}$ Insira Sarbeen and Jayaraj used different histological stains to study cementum under a light microscope. ${ }^{20}$ Ramamoorthy et al. used natural alternatives for chemicals used in histopathology laboratories. Natural alternatives to this chemical stains will have less health hazards to the technicians, pathologists, and scientists. ${ }^{21}$ In the present study, an innovative "Pravara" stain was used to stain the ground sections of extracted teeth. The powder of this stain is obtained from the fruits of a leafless tree called T. chebula (Harad). ${ }^{4}$ Terminalia chebula is also used as the main ingredient in many Ayurvedic formulations that are used to treat kidney and liver dysfunctions. ${ }^{22}$ Terminalia chebula contains chebulinic acid and terflavin B, a type of tannin. ${ }^{23}$ The stain obtained does not fade away with time, that is, around 6 months. The same stained sections were viewed after 6 months (Fig. 2). However, comparison of grading of sections with duration was not performed in the present study. Future studies in this regard to compare the grades of the stained section with time could be carried out for validation of results.

\section{Conclusion}

Innovative "Pravara" stain is a simple, economical, quick, and effective staining method for the ground section of the tooth.

\section{Clinical Significance}

This can reduce the cost of medical diagnosis. This research focused on providing an eco-friendly, cost-effective substitute.

\section{ACKnowledgments}

Thank full to Rural Dental College, Pravara Institute of Medical Sciences.

\section{RefERENCES}

1. Tan N, Thentamil A, Jacob M. Hard tissue architecture of tooth-no strain with stain. J Acad Dent Educ 2017;3(1):5-9. DOI: 10.18311/ jade/2017/16448.

2. Lakshmi TA, Sumitra V, Victor R. Application of MV10B stain for paraffin sections of teeth. Int J Health Sci Res 2013;3(8):17-21.

3. Brewer HE, Shellhamer RH. Stained ground sections of teeth and bone. Stain Technol 1956;31(3):111-114. DOI: 10.3109/10520295609113787.

4. "Terminalia chebula Retz". Germplasm Resources Information Network (GRIN). Agricultural Research Service (ARS), United States Department of Agriculture (USDA). Retrieved 6 Aug 2016.

5. Charles DK, Condon K, Cheverud JM, et al. Cementum annulation and age determination in homo sapiens. I. tooth variability and observer error. Am J Physical Anthropol 1986;71(3):311-320. DOI: 10.1002/ ajpa.1330710306.

6. Gibb T, Oseto C. Arthropod Collection and Identification: Laboratory and Field Techniques. San Diego, California: Elsevier Academic Press Publications; 2006. p. 75.

7. Shukla D, Vinuth DP, Sowmya SV, et al. Cementum made more Visual. J Forensic Odontostomatol 2012;30(1):29-37.

8. Yadav SM, Wakode R, Kumar S, et al. Ground sections of teeth: histopathological study modality. Int J Res Med Sci 2019;7(4): 1384-1387. DOI: 10.18203/2320-6012.ijrms20191359.

9. Prasad BK, Kumar P, Tyagi YK. Age determination: in relation to specific demands of forensic practice. Anil Aggrawal's internet. J Forensic Med Toxicol 2003;4(2):4-7.

10. Charles DK, Condon K, Cheverud JM, et al. Estimating age at death from growth layer groups in cementum. In: Iscan MY, Kennedy KAR. Age Markers in the Human Skeleton. Springfield: Charles C. Thomas; 1989. pp. 277-316.

11. Robbins $G$, Lukacs JR. Cementum annulations and age estimation in an early holocene population. J Odondol 2004;13:212-227.

12. Little MF, Cueto CS, Rowley J. Chemical and physical properties of altered and sound enamel. I.ASH, $\mathrm{Ca}, \mathrm{P}, \mathrm{CO}_{2}, \mathrm{~N}$, water, microradiolucency and density. Arch Oral Biol 1962;7:173-184. DOI: 10.1016/0003-9969(62)90005-5.

13. Alturkistani HA, Tashkandi FM, Mohammedsaleh ZM. Histological stains: a literature review and case study. Glob J Health Sci 2015;8(3):72-79. DOI: 10.5539/gjhs.v8n3p72.

14. Lillie RD, Pizzolato P, Donaldson PT. Hematoxylin substitutes. A study of phenocyanin TC and the use of after chromemordanting in histology. Am J ClinPathol 1975;63(6):876-885.

15. Lillie RD, Pizzolato P, Welsh RA, et al. A consideration of substitutes for alum hematoxylin in routine histologic and cytologic diagnostic procedures. Am J Clin Path 1973;60(6):817-819. DOI: 10.1093/ ajcp/60.6.817.

16. Lillie RD, Pizzolato P, Donaldson PT. Hematoxylin substitutes: a survey of mordant dyes tested and consideration of the relation of their structure to performance as nuclear stains. Stain Technol 1976;51(1):25-41. DOI: 10.3109/10520297609116665.

17. Lillie RD, Pizzolato P, Donaldson PT. Hematoxylin substitutes: fluorone black and methyl fluoroneblack (9-phenyl- and 9-methyl-2,3,7trihydroxy-6-fluorone) as metachrome iron alum mordantdyes. Stain Technol 1975;50(2):127-131. DOI: 10.3109/10520297509117046. 
18. Hogg RM, Simpson R. An evaluation of solochrome cyanine R.S. as a nuclear stain similar to haematoxylin. Med Lab Technol 1975;32(4):301-306.

19. Llewellyn $\mathrm{BD}$. Mordant blue 3: a readily available substitute for hematoxylin in the routine hematoxylin and eosin stain. Stain Technol 1974;49(6):347-349. DOI: 10.3109/10520297409117010.

20. Insira Sarbeen J, Jayaraj G. Light microscopic study of cementum under different histological stains. J Pharm Sci Res 2015;7(9): 720-723.

21. Ramamoorthy A, Ravi S, Jeddy N, et al. Natural alternatives for chemicals used in histopathology lab: a literature review. J Clin
Diagn Res 2016;10(11):EE01-EE04. DOI: 10.7860/JCDR/2016/23420 8860.

22. Tewari D, Mocan A, Parvanov ED, et al. Ethnopharmacological approaches for therapy of jaundice: part II. highly used plant species from Acanthaceae, Euphorbiaceae, Asteraceae, Combretaceae, and Fabaceae families. Front Pharmacol 2017;8:519. DOI: 10.3389/ fphar.2017.00519.

23. Han Q, Song J, Qiao C, et al. "Preparative isolation of hydrolysable tannins chebulagic acid and chebulinic acid from Terminalia chebula by high-speed counter-current chromatography" (PDF). J Sep Sci 2006;29(11):1653-1657. DOI: 10.1002/jssc.200600089. 